\title{
Self-expandable covered metallic stent as a conduit for pancreatic stone extraction
}

A 50-year-old man was referred for evaluation of alcohol-related chronic relapsing pancreatitis. Initial endoscopic retrograde cholangiopancreatography (ERCP) revealed a dilated pancreatic duct with a stone proximal to a distal stricture. The stricture was dilated to $6 \mathrm{~mm}$ using a balloon, and an 8.5-Fr plastic stent was placed to ensure drainage. ERCP 2 months later showed no improvement in the stricture and a 10-Fr stent was placed. Repeat pancreatography 2 months later ( $\vee$ Video 1) revealed a persistent distal stricture with a floating ovoid-shaped stone $(6 \times 10 \mathrm{~mm})$ in the proximally dilated duct ( $\triangleright$ Fig. 1 a). The stricture was dilated to $6 \mathrm{~mm}$ ( $\triangleright$ Fig. $\mathbf{1}$ b), and an $8 \mathrm{~mm} \times$ $4 \mathrm{~cm}$ fully covered Gore Viabil (Conmed Corp., Utica, New York, USA) self-expandable metallic stent (SEMS) was placed across the stricture. A rat-tooth forceps was passed through the SEMS and the stone was grasped ( $\triangleright$ Fig.2) under fluoroscopic guidance. The stone and stent were then simultaneously extracted from the duct and removed from the pa-
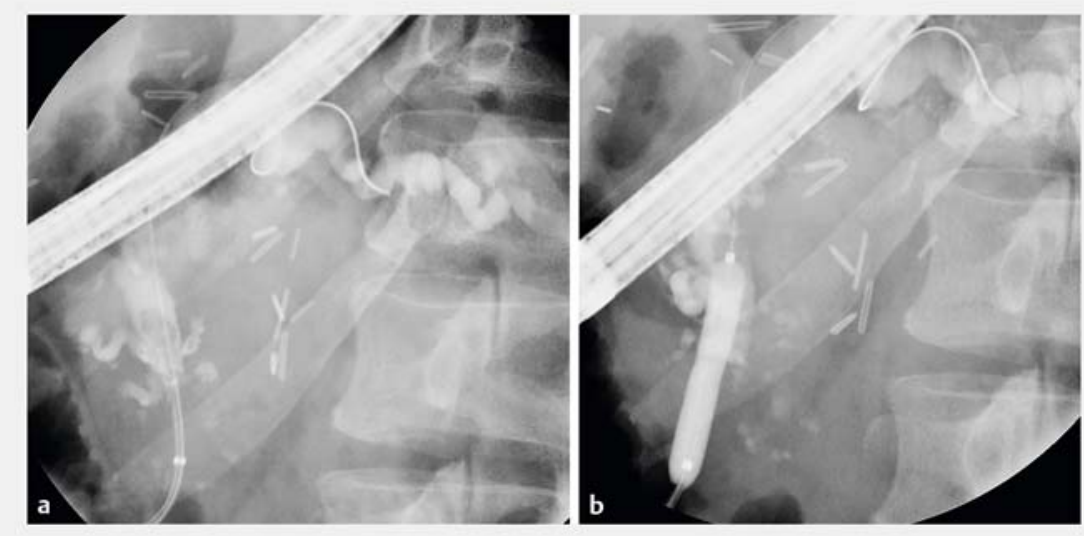

- Fig. 1 Pancreatography. a Distal stricture with associated stone. b Dilation of the pancreatic duct stricture.

tient ( $\triangleright$ Fig. 3, $\triangleright$ Video 1 ). There were no post-procedural complications.

Ductal hypertension, as a result of obstruction from pancreatic duct stones and strictures in chronic pancreatitis, is believed to be the major cause of pain and recurrent pancreatitis [1]. Treat- ment options for pancreatolithiasis vary depending on stone location and size [2, 3]. The 2015 European Society of Gastrointestinal Endoscopy recommends the use of ERCP as first-line therapy in patients with a small number of stones with a diameter of $<5 \mathrm{~mm}$ in the body
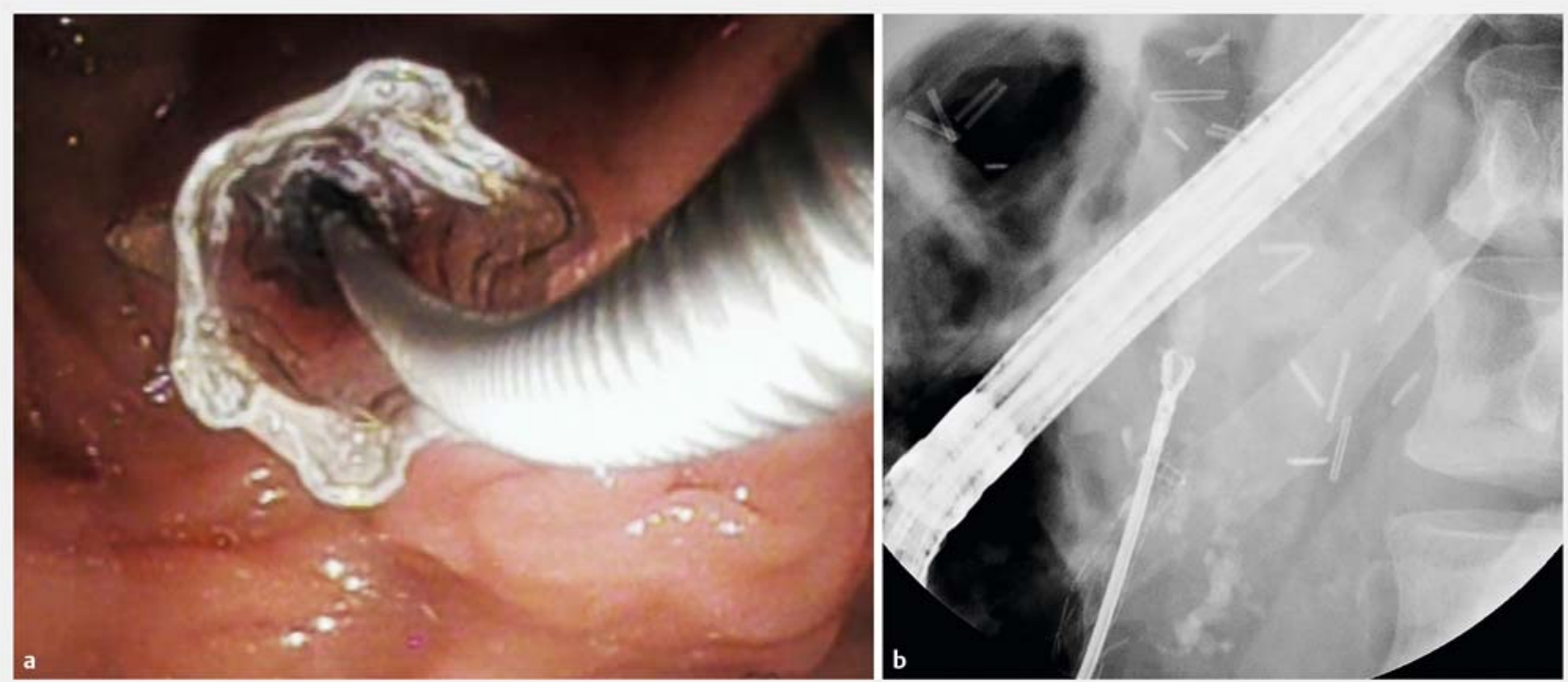

- Fig. 2 Use of the rat-tooth forceps. a Endoscopic image showing advancement of rat-tooth forceps through the self-expandable metallic stent. b Fluoroscopic image showing rat-tooth forceps grasping the pancreatic duct stone. 


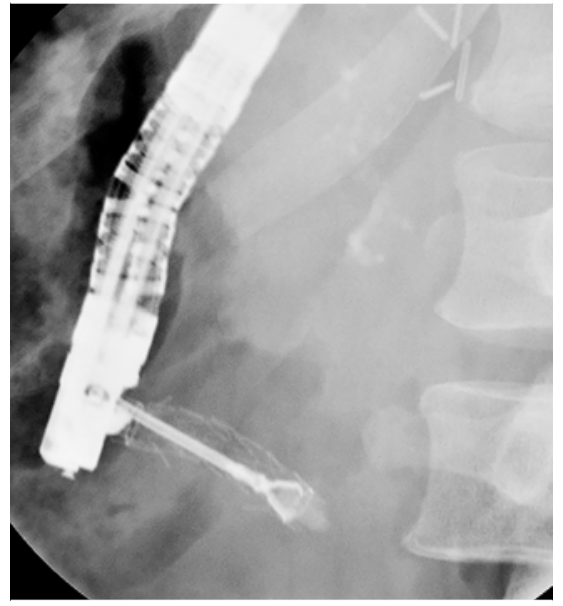

- Fig. 3 Fluoroscopic image showing simultaneous removal of the pancreatic duct stone and metallic stent.

\section{Corresponding author}

extracorporeal shock wave lithotripsy prior to ERCP is recommended [4]. We present a unique method of pancreatic stone removal using a fully covered SEMS as a conduit for passage of a rattooth forceps across a distal stricture to facilitate pancreatic stone extraction.

Endoscopy_UCTN_Code_TTT_1AR_2AH

\section{Competing interests}

None

The authors

Heather Branstetter, Umangi Patel, Prashant Kedia, Paul R. Tarnasky

Gastroenterology, Methodist Dallas Medical Center, Dallas, Texas, United States

Fax: +1-214-947-3835

\section{References} 29-37

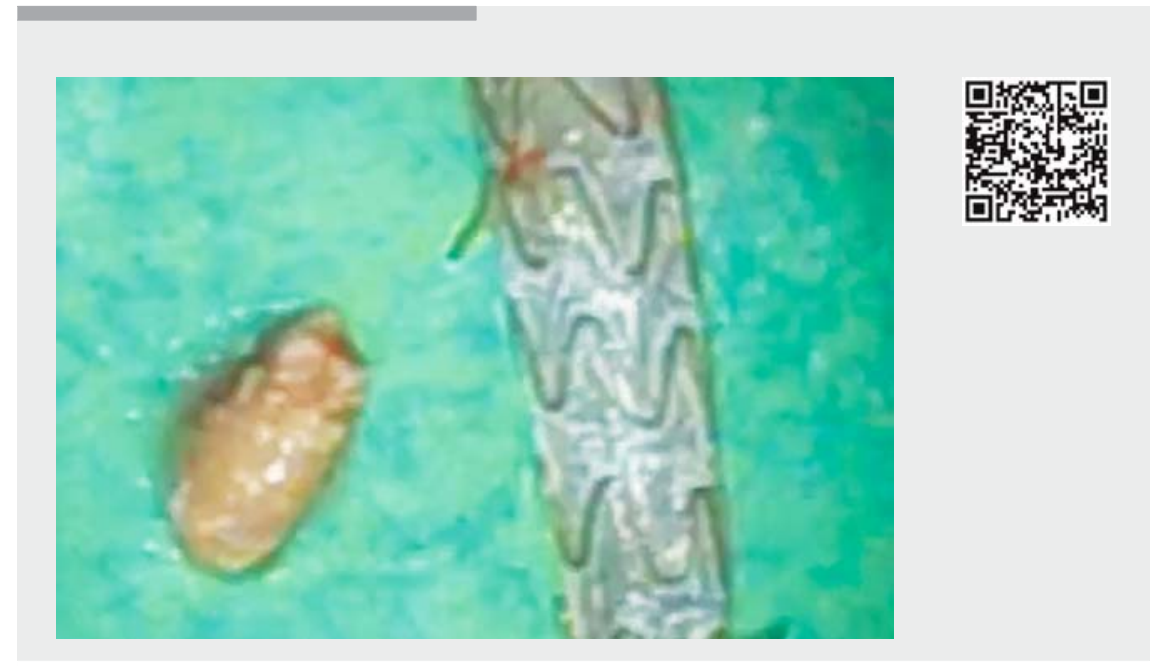

$\checkmark$ Video 1 Removal of a pancreatic duct stone with the aid of a self-expandable metallic stent.

\section{Heather Branstetter, MD}

Gastroenterology, Methodist Dallas Medical Center, 1441 N Beckley Avee, Dallas, Texas 75203-1201, United States

hbranstetter@tddctx.com

[1] Choi E, Lehman G. Update on endoscopic management of main pancreatic duct stones in chronic calcific pancreatitis. Korean J Intern Med 2012; 27: 20 - 29

[2] Beyna T, Neuhaus H, Gerges C. Endoscopic treatment of pancreatic duct stones under direct vision: revolution or resignation? Systematic review. Dig Endosc 2018; 30:

[3] Chandrasekhara V, Chathadi KV. ASGE Standards of Practice Committee et al. The role of endoscopy in benign pancreatic disease. Gastrointest Endosc 2015; 82: 203 214

[4] Dumonceau J, Delhaye M, Tringali A et al. Endoscopic treatment of chronic pancreatitis: European Society of Gastrointestinal Endoscopy Clinical Guideline. Endoscopy 2012; 44: $784-800$

\section{Bibliography}

DOI https://doi.org/10.1055/a-0640-2421

Published online: 3.7.2018

Endoscopy 2018; 50: E262-E263

(c) Georg Thieme Verlag KG

Stuttgart · New York

ISSN 0013-726X

\section{ENDOSCOPY E-VIDEOS}

https://eref.thieme.de/e-videos

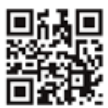

Endoscopy E-Videos is a free access online section, reporting on interesting cases and new techniques in gastroenterological endoscopy. All papers include a high quality video and all contributions are freely accessible online.

This section has its own submission website at https://mc.manuscriptcentral.com/e-videos 